\title{
A Case for Pre-Exposure Prophylaxis of High- Risk Groups against Rabies in India
}

\author{
Ajit Shewale, Tushar Nale ${ }^{2}$, Monal Daptardar ${ }^{3}$, Simmi Tiwari ${ }^{4}$
}

1,2,3,4 Division of Zoonotic Diseases Programme, National Centre for Disease Control, 22 - Shamnath Marg Civil Lines, Delhi, India. DOI: https://doi.org/10.24321/0019.5138.202118

\section{I $\quad \mathbf{N} \quad \mathbf{F} \quad \mathbf{O}$}

\section{Corresponding Author:}

Ajit Shewale, Division of Zoonotic Diseases Programme, National Centre for Disease Control, 22 - Shamnath Marg Civil Lines, Delhi, India. E-mail Id:

adshewale12527@gmail.com

\section{Orcid Id:}

https://orcid.org/0000-0001-8301-5723

How to cite this article:

Shewale A, Nale T, Daptardar M, Tiwari S. A Case for Pre-Exposure Prophylaxis of High-Risk Groups against Rabies in India. J Commun Dis 2021; 53(1): 110-116.

Date of Submission: 2021-02-03

Date of Acceptance: 2021-03-02

\section{$\begin{array}{llllllllllll}\text { I } & \mathbf{N} & \mathbf{T} & \mathbf{R} & \mathbf{O} & \mathbf{D} & \mathbf{U} & \mathbf{C} & \mathbf{T} & \mathbf{I} & \mathbf{O} & \mathbf{N}\end{array}$}

Rabies is a fatal zoonotic disease which has tormented humanity since antiquity. It is transmitted after the bite of a rabid animal and is 100 $\%$ fatal if timely intervention of appropriate wound management and Anti Rabies Prophylaxis is not given to the animal bite victims. About $96 \%$ of the mortality and morbidity is associated with dog bites.

In India, around 6-7 million animal bites are reported under Integrated Disease Surveillance Program and as per WHO estimates In India, 18000 to 20000 cases of Rabies occur every year, contributing to $36 \%$ of the world's deaths from the disease. Global call by international agencies (WHO, OIC, FAO) for rabies elimination by 2030 ("Zero By Thirty").

The Ministry of Health \& Family welfare has already rolled out the National Rabies Control Program as a Centrally Sector Scheme in the $12^{\text {th }}$ financial year. Under this programme, National Action for dog mediated Rabies Elimination from India (NAPRE) has been prepared through a collaborative multidisciplinary "One health" approach. The NAPRE has identified stakeholders from Public Health, Animal Husbandry, Environment \& Forest, along with the Urban and Rural Governing Bodies, at the Central and the State level. These stakeholders would be undertaking the activities planned as the strategic framework in the NAPRE i.e. canine vaccination, Timely and appropriate PEP and Pre-Exposure for high-risk individuals, i.e. Children, beggars, animal handlers and veterinarians.

The current communication, highlights the need for Pre-Exposure prophylaxis (Pre-PEP) of high-risk groups against Rabies in India.

\section{Rationale}

In India, Rabies affects mainly people of lower socio-economic status and children between the ages of 5 and 15 years. In a study conducted among 529 animal bite cases in 2019 it was found that Majority of the bite victims were from the age group of $15-59$ years $(66.7 \%),<15$ years $(21.7 \%)$ and elderly $>60$ years $(11.6 \%)$ And $(78.5 \%)$ were below poverty line. The study data also showed that most of the subjects had category III (54.4\%) or category II exposures (43.1\%), who needs immediate PEP. ${ }^{1}$ Thus Children are the most commonly exposed age group to Rabies in Rabies endemic areas and represent $50 \%$ of human exposures in such 
areas. Children also underestimate the danger arising from dogs, are exposed frequently to bite accidents.

Outdoor children are especially exposed for dog bite due to presence of free roaming dogs as well as community owned dogs in the local communities. These children have a higher risk of being bitten in high risk areas on the body such as the face, head and neck. A bite in such area on the body has particularly more challenges for preventing Rabies unless there is access to immediate and appropriate medical care.

Studies revealed that most children attacked by dogs were unaware of having been bitten and their parents often ignored the attacks ${ }^{2}$ or simply treated the wounds by applying indigenous products such as hot peppers or turmeric. Only a few parents sought medical advice, usually with delay. Therefore, pre-exposure prophylaxis (PrEP) in these children would prevent several unnecessary deaths due to Rabies. Indian Academy of Pediatrics (IAP) also advocates routine pre-exposure prophylaxis for children in their recommended schedule.

In India High-risk population include homeless or street children, beggars, dog catchers etc. Street children are poor or homeless children who live on the streets in urban and rural areas. Pre-exposure prophylaxis in children, particularly street children living in high-risk areas of exposure to Rabies would reduce the number of vaccine booster doses required to only two on days 0 and 3. Pre-exposure vaccine would eliminates the need to administer Rabies Immunoglobulins (RIG), which are costly and have variable availability at all health care centers after an exposure to animal has occurred.

Studies have revealed that pre-exposure rabies prophylaxis for children are safe and immunogenic and could be given along with other pediatric vaccine. ${ }^{3}$

\section{Global Scenario}

Pre-Exposure Prophylaxis (Pre-PEP) for rabies have already been implemented at a National level in Peru and the Philippines $^{3}$ among high-risk populations.

Pre-PEP could prove beneficial among (i) remote communities where access to post exposure prophylaxis and rabies immunoglobulin is often delayed or nonexistent; (ii) situations in which the risk of exposure is high and may go unrecognized, for example, in young children or people exposed occupationally, such as veterinarians; or (iii) places where controlling Rabies in the animal reservoir is difficult, and the risk of human exposure is high, such as in the forest areas. $^{3}$ It is essential that all personnel's involved in canine rabies control activities must receive Pre-PEP because of their higher risk of exposure.

\section{Indian Scenario on Pre-exposure Prophylaxis}

In India, Rabies vaccine is currently not included in the Universal immunization programme although Indian Academy of Pediatrics (IAP) have advocated routine preexposure prophylaxis for children in their recommended schedule. ${ }^{4}$ As per the latest study WHO-APRCI 20 on awareness about Rabies $60.5 \%$ were aware of Rabies, and $39.5 \%$ had never heard of Rabies. $3.7 \%$ of respondents were aware of pre-exposure prophylaxis. ${ }^{5}$

As per National Guidelines for rabies, pre-exposure vaccination may be offered to High-Risk Groups such as below:

- Laboratory personnel handling the virus and infected material

- Clinicians and individuals who are caregivers to human rabies cases

- Veterinarians, animal handlers and dog catchers

- Wildlife \& forest personnel

- Animal quarantine officers

- Travelers from Rabies free areas to Rabies endemic areas

\section{Schedule}

Pre-exposure vaccination is administered as one full vial of vaccine intramuscularly, in case of intradermal route $0.1 \mathrm{ml}$ to be given on days 0,7 and either day 21 or 28 .

High-risk groups should have their neutralizing antibody titers checked every six months during the initial two-year period after the primary vaccination. If it is less than $0.5 \mathrm{IU} /$ $\mathrm{ml}$, a booster dose of vaccine should be given. Subsequently, sero-monitoring is recommended every two years. Vaccineinduced immunological memory persists in most cases for years and a booster would be recommended only when the Rabies virus-neutralizing antibody titers have dropped to less than $0.5 \mathrm{lU} / \mathrm{mL}$.

Vaccinated individuals exposed to Rabies virus after successful pre-exposure immunization would require only two booster injections of vaccine given on days 0 and3. There is no need for RIG.

\section{Annual Incidence of Animal Bites in India}

As per data available on animal bites on Integrated Disease Surveillance Programme in India, the Annual Incidence of animal bites varies considerably across States and Districts. WHO-APCRI study had estimated that India has $1.7 \%$ incidence of animal bites and a Global incidence ranging from 0.6 to $5 \% .5$ As per the data available on Integrated Disease Surveillance Programme, few States have incidence of animal bites more than the National Average of $1 \%$ of animal bites. i.e. Odisha, Chhattisgarh, Karnataka, Andhra 
Pradesh, Puducherry, Punjab, Tamil Nadu, Odisha, West Bengal, Bihar. Variations are observed in incidence of animal bites at the district level (Table 1). As per WHO, preexposure prophylaxis should be considered in a population where the risk of annual animal bite exceeds $5 \%$. As per our estimates, 13 states have shown more than $5 \%$ of incidence of animal bites among children less than 18 years of age is reported from few districts.i.e.Odisha, Chhattisgarh, Karnataka, Andhra Pradesh, Puducherry, Punjab, Tamil Nadu, Odisha, West Bengal, Bihar. Approximate estimates for all districts based on WHO - APCRI study have been worked out to address the issue of underreporting under current IDSP system.

\section{Status of Other High-Risk Groups for Rabies}

\section{Street Children's}

Exact data on number of street children in India is not known however as per the estimates by UNICEF in 2006 there were at least a 100 million street children in the world and 11 million in India. Almost $10 \%$ of the total population of children in the world live on Indian streets. ${ }^{6}$ An estimated 25 million children live on streets in India. ${ }^{7}$ Indian embassy assessed that 314,700 street children live in cities like Mumbai, Kolkata, Chennai, Kanpur, Bangalore, Kanpur and Hyderabad and about 100,000 street children within Delhi. National Policy for Children adopted by the Government of India (2013) and National Plan of Action for Children (2016) by the Ministry of Women and Child Development highlighted the need for providing health care to street children.

The Exact number of street children affected with animal bites or Rabies is not available. However, it has been observed that in India, and in particular street children are most the common victims of animal bites since unvaccinated community dogs and free roaming dogs are commonly observed on the streets and in \& around public places, school playgrounds gardens etc.

Street children are more likely to access the government health facility for animal bite management and if services of Anti- Rabies Vaccine and Anti- Rabies Serum are not available easily then such cases are most likely to miss their doses of vaccine.

As rabies is 100 per cent fatal disease, therefore it needs to be ensured that these children receive the vaccine at the right time and as per the schedule. Hence, if such children are provided with Pre-exposure prophylaxis, a number of booster vaccine doses required by them would only be two (i.e. on days 0 and 3.) It also eliminates the need to administer Rabies Immunoglobulin (RIG), which is costly and may not be available at all time and all the place after an exposure to animal bite.

\section{Proposed Operationalization of Pre-exposure Prophylaxis for Street Children}

Pre-exposure prophylaxis of high-risk groups is one of the strategies adopted under the National Action Plan for Dog Mediated Rabies Elimination from India. Funds for the proposed activity may be proposed under existing Government of India mechanism, National Free Drug Initiative of National health mission under which funds for Anti-Rabies Vaccine (ARV) \& Anti Rabies Serum (ARS) are provided.

- Advocacy has been done to the state to encourage them to frame a joint State Level Action Plan as per their needs and in consonance with the NAPRE which would guide the states on the technical as well as the administrate framework

- Pre-exposure prophylaxis of street children should be included in state level action plans after consultation with pertinent stakeholders. i.e. Ministry of Women and Child Development (WCD), Ministry of social welfare and justice, relevant NGOs and private/ professional organizations working for street children

- The plan should include an enumeration of street children in the urban area/rural areas by Women and Child development department \& relevant NGOs/ private/ professional organizations working for street children.

- $\quad$ Based on the requirement for doses (2 doses for each child) requirement for the individual district should be arrived.

- Since the exact address of street children is not always tractable, Micro planning should be done for pre-exposure vaccination by the health dept. in coordination with WCD \& NGOs/ private/ professional organizations as per their operational feasibility

- Mircoplans should be planned in such a way that in a campaign mode, all street children from urban or rural area would be included. Intensive IEC campaigns must be conducted prior to campaign through local stakeholders (NGOs, representatives of local bodies, Social organizations, volunteers etc.) to ensure the maximum coverage of all street children.

- The health department should be equipped with the Logistic requirements of such vaccination plans (in terms of Vaccine, Syringes, vials, Transport containers, Cold chain maintenance, stationary and other logistic items).

- Separate nodal officers should be appointed from each department for strengthening the coordination between the departments.

- State level committee on Rabies programme should evaluate the proposed plan and provide suitable recommendations. 
- $\quad$ The District Nodal officer under the NRCP \& DNO-WCD should undertake the activity in coordination NGOs / private/professional organizations As per their district level micro plans.

- Each child should receive rabies vaccination card for future reference.

\section{Financial Implications}

From the National level, funds for ARV will be supported through National Free Drug Initiative. Rest of the funds for other logistic (Syringes, transport containers, stationery, transport cost, mobilization cost etc.) may be provided by the state government.

Approximate cost ARV for pre-exposure prophylaxis of all children at the rate of Rs.75 per child considering that two doses for each child would cost Rs. 50. After include the cost considering wastage of one dose the approximate cost of ARV is estimated to be as to Rs. 3522.46 crores.

While for pre-exposure prophylaxis of street children assuming that $1 \%$ of the total children are street children total cost estimated for prophylaxis would be Rs. 35.22 crores.

For districts having animal bite prevalence of more than 5 $\%$ as per the WHO -APCRI data, the total cost for ARV for pre-exposure prophylaxis is approximately Rs 100 crores for all children while only for street children is around Rs 1.00 crores.

\section{Conclusion}

Thus it is evident from above that in India to eliminate the "Rabies by 2030" strong measures as highlighted in NAPRE are required which would also include pre-exposure prophylaxis of high risk groups especially among homeless street children.

Therefore, in view of operational feasibility, it is proposed that pre-exposure prophylaxis of street children to be piloted in high prevalence districts followed by in all-district .Further, based on cost effectiveness studies \& inputs from relevant stakeholders/ expert groups, government would need to consider pre-exposure prophylaxis of all children in selected states/ districts with significant prevalence of animal bites.

\section{Conflict of Interest: None}

\section{References}

1. Haradanhalli RS, Hanumanthaiah AND, Varadappa ST. Cost of rabies post exposure prophylaxis in different healthcare settings in six states of India. Indian Journal of Public Health 2019; 63(5): 44.

2. Sridhar PV, Shanmukappa, Vinay $M$ et al. Profile of children bitten by dogs, reporting to a government tertiary care hospital and their compliance to post exposure prophylaxis. Journal of Evolution of Medical and Dental Sciences 2014; 5294.

3. Kessels JA, Recuenco S, Navarro-Vela AM et al. Preexposure rabies prophylaxis: a systematic review. Bull World Health Organ 2017; 95(3): 210-9C.

4. Indian Academy of Pediatrics (IAP) Recommended Immunization Schedule for Children Aged 0 through 18 years India, 2014 and Updates on Immunization. Accessed February 9, 2021. Available from: https:// www.indianpediatrics.net/oct2014/oct-785-803.html.

5. World Health Organization - Association for Prevention and Control of Rabies in India (APRCI): Indian Multicentric Rabies Survey, 2017. Accessed February 9, 2021. Available from: https://www.who.int/ publications-detail-redirect/world-health-organization--association-for-prevention-and-control-of-rabies-inindia-(aprci)-indian-multicentric-rabies-survey-2017.

6. Narayan S. Preventing-substance abuse among street children in India: a literature review. Health Science Journal 2013; 7(2).

7. Singh A, Purohit B. Street Children as a Public Health Fiasco. Peace Review 2011; 23(1): 102-9. 


\section{Annexure- I}

Table I.Districts with high Annual animal bite Incidence in India (based on IDSP data and WHO -APCRI estimates :calculated) :Year 2019

\begin{tabular}{|c|c|c|c|c|c|c|c|}
\hline $\begin{array}{l}\text { S. } \\
\text { No. }\end{array}$ & State Name & District Name & $\begin{array}{l}\text { Popul- } \\
\text { ation }\end{array}$ & $\begin{array}{c}\text { Annual } \\
\text { Incidence of } \\
\text { animal bites } \\
\text { in general } \\
\text { population (as } \\
\text { per WHO -APCRI } \\
\text { estimates- } \\
\text { Calculated) (\%) }\end{array}$ & $\begin{array}{l}\text { Annual } \\
\text { Incidence } \\
\text { of animal } \\
\text { bites in } \\
\text { general } \\
\text { population } \\
\text { (Source: } \\
\text { IDSP) (\%) }\end{array}$ & $\begin{array}{c}\text { Annual } \\
\text { Incidence of } \\
\text { animal bites } \\
\text { in Children } \\
\text { (per WHO } \\
\text {-APCRI } \\
\text { estimates- } \\
\text { Calculated) } \\
(\%) \\
\end{array}$ & $\begin{array}{l}\text { Annual } \\
\text { Incidence } \\
\text { of Animal } \\
\text { bite in } \\
\text { childrens } \\
\text { (Source: } \\
\text { IDSP )\% }\end{array}$ \\
\hline 1. & West Bengal & Nandigram-Hd & 5803 & 76 & 32 & 92 & 38 \\
\hline 2. & West Bengal & $\begin{array}{c}\text { Diamond Harbour- } \\
\text { Hd }\end{array}$ & 41802 & 43 & 18 & 52 & 22 \\
\hline 3. & West Bengal & Rampurhat-Hd & 57833 & 36 & 15 & 44 & 18 \\
\hline 4. & Odisha & $\begin{array}{c}\text { Khurda } \\
\text { (Bhuvaneshwar) }\end{array}$ & 120204 & 28 & 12 & 34 & 14 \\
\hline 5. & Chhattisgarh & Janjgir & 40561 & 27 & 11 & 32 & 13 \\
\hline 6. & Karnataka & Haveri & 67102 & 22 & 9 & 26 & 11 \\
\hline 7. & Andhra Pradesh & Kadapa & 344893 & 18 & 7 & 22 & 9 \\
\hline 8. & Puducherry & Pondicherry & 244377 & 17 & 7 & 21 & 9 \\
\hline 9. & Punjab & Nawanshahr & 46023 & 17 & 7 & 20 & 8 \\
\hline 10. & Tamil Nadu & Udagamandalam & 88,430 & 15 & 6 & 18 & 7 \\
\hline 11. & Odisha & Nawarangpur & 36945 & 14 & 6 & 17 & 7 \\
\hline 12. & West Bengal & Bishnupur-Hd & 138786 & 12 & 5 & 15 & 6 \\
\hline 13. & Bihar & Bhabhua & 50179 & 12 & 5 & 14 & 6 \\
\hline 14. & Tamil Nadu & Kancheepuram & 1166401 & 9 & 4 & 10 & 4 \\
\hline 15. & Kerala & Cannanore (Kannur) & 232634 & 8 & 4 & 10 & 4 \\
\hline 16. & Karnataka & Vijayapura & 327427 & 8 & 4 & 10 & 4 \\
\hline 17. & Karnataka & Belagavi & 488292 & 8 & 3 & 10 & 4 \\
\hline 18. & Uttar Pradesh & Bulandshahar & 3498507 & 8 & 3 & 10 & 4 \\
\hline 19. & Telangana & Nalgonda & 1631399 & 8 & 3 & 9 & 4 \\
\hline 20. & Uttar Pradesh & Kanshi Ram Nagar & 1436719 & 7 & 3 & 9 & 4 \\
\hline 21. & Uttar Pradesh & Baghpat & 1302156 & 7 & 3 & 8 & 3 \\
\hline 22. & Tamil Nadu & Salem & 3480008 & 6 & 3 & 7 & 3 \\
\hline 23. & Uttar Pradesh & Panchsheel Nagar & 1338211 & 6 & 3 & 7 & 3 \\
\hline 24. & Tamil Nadu & Tirunelveli & 1665253 & 6 & 2 & 7 & 3 \\
\hline 25. & Uttar Pradesh & $\begin{array}{c}\text { Gautam Budha } \\
\text { Nagar }\end{array}$ & 1648115 & 6 & 2 & 7 & 3 \\
\hline 26. & Uttar Pradesh & Sant Ravi Das Nagar & 1578213 & 5 & 2 & 7 & 3 \\
\hline 27. & Puducherry & Karikal & 200222 & 5 & 2 & 6 & 3 \\
\hline 28. & Tamil Nadu & Nagapattinam & 1614069 & 5 & 2 & 6 & 3 \\
\hline
\end{tabular}




\begin{tabular}{|c|c|c|c|c|c|c|c|}
\hline 29. & Daman\&Diu & Diu & 52056 & 5 & 2 & 6 & 2 \\
\hline 30. & Rajasthan & Bhilwara & 359483 & 5 & 2 & 6 & 2 \\
\hline 31. & Tamil Nadu & Cuddalore & 2600880 & 5 & 2 & 6 & 2 \\
\hline 32. & Tamil Nadu & Thiruvarur & 1268094 & 5 & 2 & 6 & 2 \\
\hline 33. & Uttar Pradesh & Meerut & 3447405 & 5 & 2 & 6 & 2 \\
\hline 34. & Rajasthan & Bharatpur & 2549121 & 5 & 2 & 6 & 2 \\
\hline 35. & Uttar Pradesh & Hathras & 1565678 & 5 & 2 & 6 & 2 \\
\hline
\end{tabular}

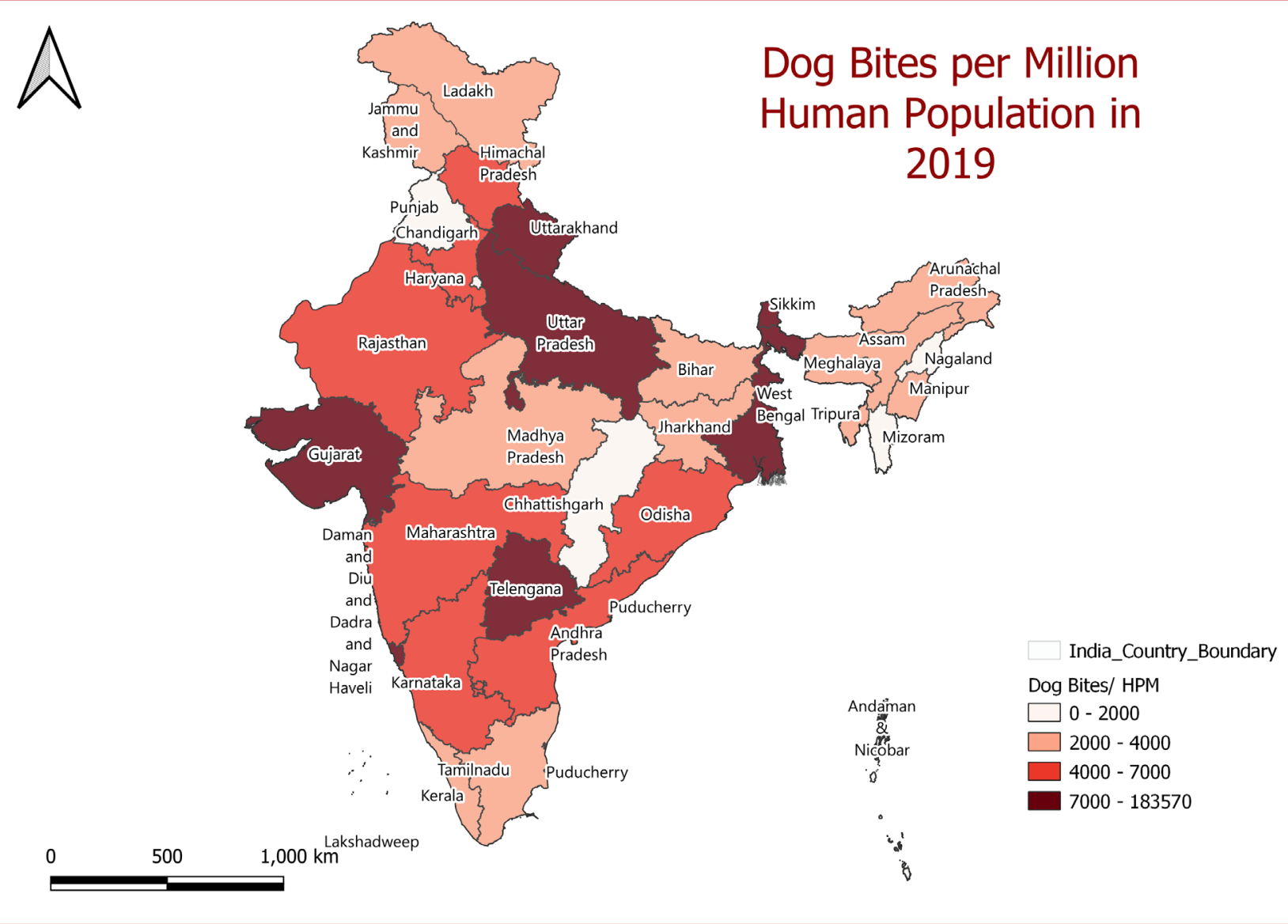

Figure I.Total Dog bites per million human population in 2019. Software QGIS. Data source-Dog bites in 2019 from IDSP, GOI. Census data 2011 


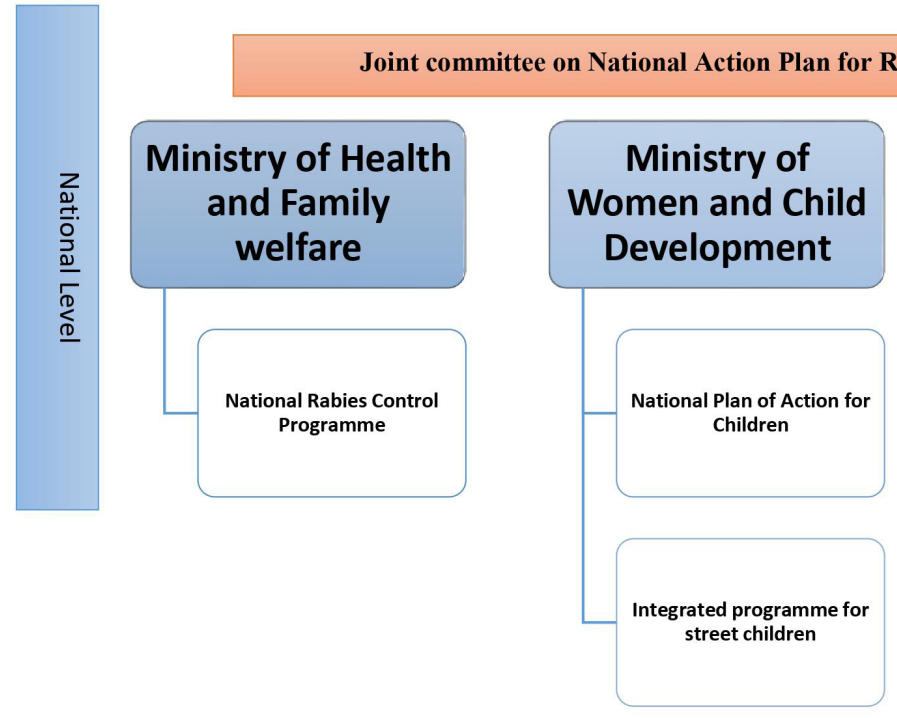

\section{Ministry of Social Justice and welfare \\ Assistance to Non- Governmental \\ Organizations working fo the welfare of disadvantaged section i.e Street Children's}
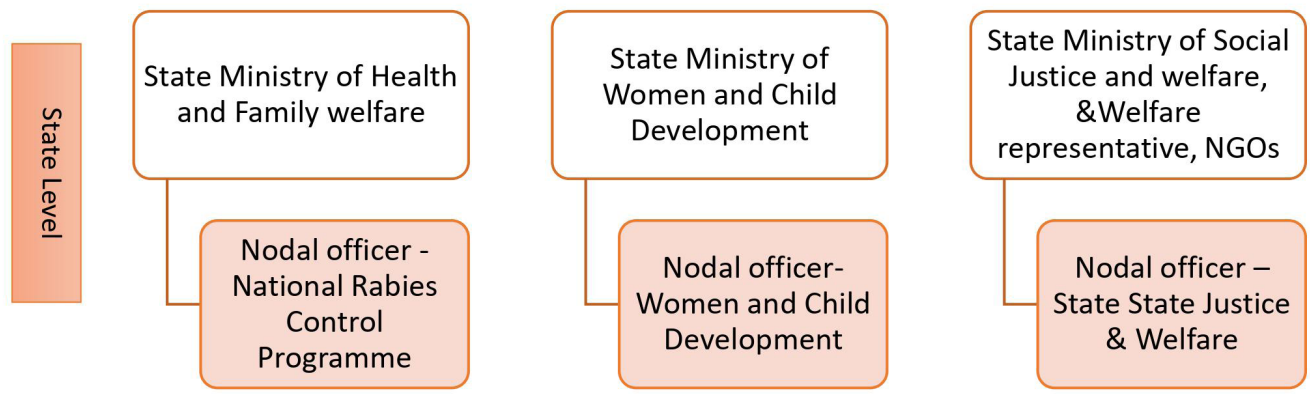

Joint committee on District Action Plan for Rabies Elimination- Chaired by District Magistrate

\section{District Health and Family welfare \\ Dept. \\ District Nodal officer -National Rabies Control Programme \\ Medical officer, Frontline health worker, ANM, ASHA}

\section{District Women \\ and Child \\ Development Dept}

Child

Development

welfare officer

Mukhya Sevika, AWW

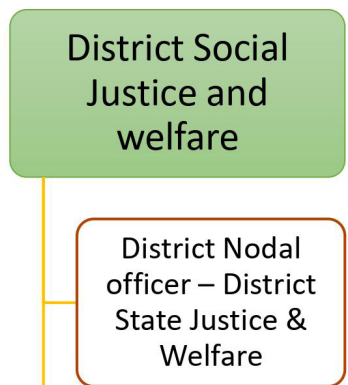

Representative officials and representatives from NGOs

Figure 2.Proposed Organizational Structure for Implementation of PrEP for street Children 